\title{
Techno-economic and uncertainty analysis of in situ and ex situ fast pyrolysis
}

\section{for biofuel production}

\author{
Boyan Li ${ }^{\mathrm{a}}$, Longwen Ou ${ }^{\mathrm{a}}$, Qi Dang ${ }^{\mathrm{a}, \mathrm{b}}$, Pimphan Meyer ${ }^{\mathrm{c}}$, Susanne Jones ${ }^{\mathrm{c}}$, \\ Robert Brown $^{a, b}$, Mark Wright ${ }^{a, b}$ \\ a Department of Mechanical Engineering, lowa State University, Ames, IA 50010 \\ ${ }^{\mathrm{b}}$ Bioeconomy Institute, lowa State University, Ames, IA 50011 \\ ${ }^{\mathrm{c}}$ Pacific Northwest National Laboratory, Richland, WA 99352 \\ *Corresponding Author (markmw@iastate.edu)
}

Keywords: pyrolysis, in situ, ex situ, techno-economics analysis, uncertainty analysis

\begin{abstract}
This study evaluates the techno-economic uncertainty in cost estimates for two emerging technologies for biofuel production: in situ and ex situ catalytic pyrolysis. The probability distributions for the minimum fuel-selling price (MFSP) indicate that in situ catalytic pyrolysis has an expected MFSP of $\$ 1.11$ per liter with a standard deviation of 0.29 , while the ex situ catalytic pyrolysis has a similar MFSP with a smaller deviation $(\$ 1.13$ per liter and 0.21 respectively). These results suggest that a biorefinery based on ex situ catalytic pyrolysis could have a lower techno-economic uncertainty than in situ pyrolysis compensating for a slightly higher MFSP cost estimate. Analysis of how each parameter affects the NPV indicates that internal rate of return, feedstock price, total project investment, electricity price, biochar yield
\end{abstract}


and bio-oil yield are parameters which have substantial impact on the MFSP for both in situ and ex situ catalytic pyrolysis. 


\section{Introduction}

Atmospheric $\mathrm{CO}_{2}$ has increased more than $35 \%$ in the last century. It will pass the critical value of 550ppm in this century, unless fossil fuels consumption is significantly reduced (Hoffert et al., 2002). As one of the biggest greenhouse gas contributors, transportation fuels have received increasing attention in recent decades. Biomass-based transportation fuels have been considered as a clean and renewable alternative to fossil fuels. Under the authority of the Energy Independence and Security Act (EISA) of 2007, the revised Renewable Fuel Standard (RFS2) mandate requires the blending of biofuels for transportation applications. Commercialscale biorefinery facilities are required to meet the goals set by EISA. Typically, large biorefinery projects processing 2000 metric tonnes per day of biomass or more, take more than four years to develop a design before startup (Myers et al., 1986). Moreover, biofuel production facilities cannot be easily modified once they have been designed and constructed (Anex et al., 2010). Therefore, a techno-economic analysis (TEA) across different platforms is needed in order to determine the most suitable pathway under given market conditions to avoid investing in enterprises with high commercialization risk. TEA can be used to understand and compare the profitability and breakdown cost for any project, therefore, it has been applied to many biorenewable systems such as corn ethanol production (Ou et al., 2014), gasification (Swanson et al., 2010), pyrolysis (Zhang et al., 2013), and hydrothermal liquefaction (Ou et al., 2015). TEA of catalytic fast pyrolysis has received growing interest in recent years in particular. Previous studies show that the minimum fuel-selling price (MFSP) of biofuel produced by pyrolysis can vary within a fairly large range (\$0.5 to \$2.1 per liter) (Anex et al., 2010; Brown et al., 2013; Thilakaratne, 2014; Wright et al., 2010), which may be attributed to several reasons: (1) 
differences in system configurations, (2) variability in assumptions for parameter values, and (3) inconsistencies in approaches to address technical and market uncertainty (Brown \& Wright, 2014).

Biomass fast pyrolysis and bio-oil upgrading technology is a promising way to convert cellulosic biomass into bio-diesel, bio-gasoline and other renewable fuels. Two related catalytic pyrolysis configurations (in situ and ex situ) are receiving growing interest because of their ability to produce gasoline and diesel range hydrocarbons (Ruddy et al., 2014). The in situ catalytic pyrolysis system combines solid phase pyrolysis reactions and catalytic vapor upgrading within a single reactor. Whereas in ex situ, also known as vapor phase upgrading, fast pyrolysis occurs in a pyrolysis reactor and then the vapor phase goes into a separate catalytic reactor where vapors are catalytically upgraded (NREL, 2015).

The different configuration for in situ and ex situ catalytic pyrolysis leads to the following outcomes: (1) the total project investment for ex situ scenario is higher than the in situ case, due to the configuration complexity associated with the ex situ scenario; (2) the ex situ configuration separates the fast pyrolysis with catalytic vapor upgrading process, which minimizes the contact between biomass pyrolysis solid residue (char and ash) and catalyst, thus reducing the effects of coking and increasing the catalyst life span. As a result, the catalyst performance is improved and the maintenance expense for the catalytic reactor is reduced; (3) the liquid product as well as the organic liquid product obtained by the in situ and ex situ catalytic pyrolysis are similar, whereas the in situ catalysis pyrolysis has a noticeably better performance in producing phenols and aromatics, according to study by Yildiz and Ruddy (Ruddy et al., 2014; Yildiz et al., 2013). 
To our knowledge, the literature does not provide a TEA comparison of in situ and ex situ pyrolysis that accounts for the process performance variability of these technologies. In order to make a sensible comparison, the data for these systems should be normalized to a common basis. Moreover, sensitivity analysis alone is insufficient to address the uncertainty of the economic analysis since there are inherent uncertainties within each of the parameters. Therefore, model parameters should be represented by appropriate probability distributions instead of static values to improve the representation of potential analysis outcomes. One of the most straightforward ways to apply uncertainty analysis is by using Monte Carlo simulation (Greenland, 2001; Hsu, 2012). Monte Carlo simulations generate parameter samples randomly to quantitatively analyze the output uncertainty level. Although there are numerous comparison studies that evaluate biomass to transportation fuel pathways, few have incorporated the use of stochastic simulations (Anex et al., 2010; Bridgwater et al., 2002; Brown \& Wright, 2014; Swanson et al., 2010; Thilakaratne, 2014; Wright et al., 2010; Zhang et al., 2013).

The objective of this paper is to create a side-by-side techno-economic comparison of in situ and ex situ catalytic pyrolysis scenarios that addresses both sensitivity and uncertainty analysis in the comparison of these technologies. In this study, we (1) collect technical and historical data for key process and economic parameters, (2) conduct stochastic runs of chemical process models for in situ and ex situ catalytic pyrolysis, (3) investigate the sensitivity range and uncertainty of the MFSP and NPV, and (3) analyze the level of significance of these parameters to the MFSP. 


\section{Materials and Methods}

\subsection{Overall process description}

This study utilizes the method developed by Brown and Wright (Brown \& Wright, 2014) and expands it to include process parameters and analyze parameter significance level. In general, this study involves four steps: (1) collecting probability distributions for key parameters; (2) modifying existing chemical process and economic models to enable stochastic evaluations; (3) developing best-fit distributions of the stochastic MFSP and NPV, and (4) analyzing the significance level of model parameters. Figure 1 in complementary materials illustrates the various steps involved in this analysis. First, historical and experimental data for key parameters are collected and adjusted. Second, best-fit distributions of key parameters were calculated and data sets with 10,000 random values for each key parameter according to their best-fit distributions were generated using Mathematica ${ }^{\mathrm{TM}}$. Third, a Visual Basic for Applications (VBA) interface was developed to import all the generated data sets of parameter values into CHEMCAD $^{T M}$, instruct CHEMCAD ${ }^{T M}$ to run through samples from the data sets, and record the corresponding output of key mass and energy results from CHEMCAD ${ }^{\mathrm{TM}}$. The MFSP of biofuels were calculated by integrating outputs from $\mathrm{CHEMCAD}^{\mathrm{TM}}$ into a 30 year discounted cash flow rate of return financial spreadsheet. Finally error bars and distributions of the MFSP, and the relative impacts of the key input parameters were determined by analyzing these economical spreadsheets and conducting the uncertainty analysis.

\subsection{Data collection}


There are hundreds of parameters involved in TEA of biofuel pathways. The scope of this study is limited to parameters with known significant impact on process profitability as identified by the Pacific Northwest National Laboratory (PNNL) (PNNL, 2013), and parameters with publically available data. The list of selected parameters is shown in Table 1.

There were some parameters applied to both in situ and ex situ cases. Historical wholesale price for feedstock and various fuels from 2007 to 2012 were gathered based on the following sources. The Energy Information Administration (EIA) provides U.S. average wholesale prices for gasoline and diesel, and industrial natural gas and electricity prices (EIA, 2014). Uncertainty of feedstock price may come from usage of variable types of feedstock and price volatility.

Feedstock price data are based on pine pulpwood prices from the Texas Forestry Service, and the mean value of the feedstock price was shifted to $\$ 80 / M T$ (Texas A\&M Forest Service). The remaining data (catalyst to biomass ratio, hydrotreating yield, first stage Hydrodeoxygenation (HDO) catalyst cost, second stage HDO catalyst cost, second Stage HDO Liquid Hourly Space Velocity (LHSV), total project investment factor, hydrotreating catalyst life, compression requirement factor, and hydrogen consumption factor) were gathered from a PNNL report (PNNL, 2013).

Energy commodity prices exhibit significant volatility due to the complex nature of the energy market (Regnier, 2007). This volatility can be captured by appropriate probability distributions. Several candidate distributions were considered: Normal, Lognormal, Exponential, Chi-Square, Cauchy, Laplace, and Logistic. The best fit distributions were determined from the Anderson- 
Darling test (Stephens, 1974). A similar approach was employed to determine the best-fit distributions for other selected key processing parameters. In some cases, the best-fit distributions were adjusted to account for differences in the expected mean value, variance, or distribution type.

Table 1 lists the best-fit distributions, mean, 10\% and 90\% confidence values for process and economic parameters. This approach relies on the assumption that historical volatility is an indicator of future volatility, and variability gathered from literature data is representative of the uncertainty in a commercial system. Limitations from these assumptions are impossible or expensive to address because of the nature of commodity markets and the difficulty of gathering experimental data for all possible process configurations.

Insert Table 1 here.

\begin{abstract}
Uncertainty of product yields of catalytic fast pyrolysis may result from variability in feedstock type, properties, compositions, etc. and is another important factor in uncertainty analysis.
\end{abstract}

Literature data from a number of sources were employed to estimate the distribution for gas, liquid and solid products from the in situ catalytic fast pyrolysis of biomass (Adam et al., 2006; Agblevor et al., 2010; Aho et al., 2008; Aho et al., 2010; Cheng et al., 2012; Lappas et al., 2002; Mante et al., 2012; Mihalcik et al., 2011; Mullen et al., 2011; Paasikallio et al., 2013;

Triantafyllidis et al., 2007; Yildiz et al., 2013). Figure 1 shows the in situ catalytic pyrolysis organic oil yield and oxygen content reported in the public literature. The variability in the data 
reflects a diversity of experimental methods and reactor designs. Best-fit distributions of organic oil (bio-oil) yield and biochar were determined based on the data reported in literature. The non-condensable gas yield was adjusted to maintain a closed mass balance across the pyrolysis process.

Mante et al (Mante et al., 2012) conducted pyrolysis experiments using crystalline Y-zeolite based catalysts with a fluidized bed reactor and hybrid poplar wood as feedstock. The organic oil yields from his studies ranged between $13.8 \%$ and $24.1 \%$. The experiments lead by Agblevor (Agblevor et al., 2010) had an organic oil yield of 21\%. A fluidized bed pyrolysis reactor and HZSM-5 acidic catalysts were used in this study, while hybird poplar wood samples served as feedstock. Paasikallio's group (Paasikallio et al., 2013) employed a fluidized bed pyrolysis reactor with ZSM-5 acidic catalysts and forest thinnings. In their experiments, the organic oil yield varied between $14 \%$ and $49 \%$. Mullen et al. (Mullen et al., 2011) conducted catalytic fast pyrolysis experiments using a fluidized bed reactor with white oak wood as feedstock. Two catalysts were chosen in this study: $\mathrm{Ca}^{2+}$ exchanged $\mathrm{Y}$ zeolite and a proprietary $\beta$-zeolite type catalyst (catalyst M), which lead to $17 \%$ and $11 \%$ organic oil yields respectively. A conical spouted-bed reactor with a HZSM-5 catalyst was employed by Olazar's group (Olazar et al., 2000). The organic oil yield from this study is $30.8 \%$ with pine sawdust as the feedstock.

Insert Figure 1 here. 
There is limited ex situ data available in the literature compared to in situ. Researchers at the National Renewable Energy Laboratory (NREL) have obtained comparable pyrolysis oil yields from ex situ catalytic pyrolysis as in situ under similar operating conditions. Therefore, this study adjusts the in situ to reflect the similarity in yields from recent ex situ catalytic pyrolysis experiments at NREL. To obtain the ex situ distributions, the in situ distribution mean was shifted to the expected ex situ yield and the variance was lowered based on engineering judgment. Ex situ experiments have shown more consistent yield results than in situ by avoiding contact between catalysts and biomass, char, and ash. Figure 2 in complementary materials shows the comparison of biochar and bio-oil yield (wt. \%) distributions between in situ and ex situ cases. Pyrolysis non-condensable gas yields are determined by difference. The mean bio-oil yields for both in situ and ex situ cases are around 43 wt. \%.

\subsection{Modeling and analysis}

In situ and ex situ CHEMCAD ${ }^{\mathrm{TM}}$ models for 2000 dry metric ton biomass per day biorefineries were developed by PNNL and lowa State University (ISU). The catalytic pyrolysis process for producing gasoline and diesel is described in Figure 2. The in situ configuration conducts the fast pyrolysis and catalytic vapor upgrading processes within the same reactor. The ex situ configuration employs a separate catalytic vapor phase upgrading reactor system, as shown in figure 2, right after the non-catalytic fast pyrolysis reactor.

Insert Figure 2 here. 
Data sets consisting of 10,000 samples of bio-oil and biochar yields for both in situ and ex situ were obtained based on their distributions. The generated bio-oil and biochar yield data sets for in situ and ex situ were applied to the in situ and ex situ CHEMCAD ${ }^{\mathrm{TM}}$ models respectively. Excel VBA code was developed to import the stochastic samples of parameter values into CHEMCAD ${ }^{T M}$, and record the corresponding output of key mass and energy results from CHEMCAD $^{\mathrm{TM}}$. These outputs were integrated into financial spreadsheets to calculate production costs and the biofuel MFSPs. Mathematica ${ }^{\mathrm{TM}}$ was employed to analyze the financial spreadsheets and conduct the uncertainty analysis. Uncertainty analysis results were reported as error bars and distributions of the MFSP, and the relative impacts of the key input parameters. P-values were employed to determine the significance of model parameters using a 0.05 threshold.

\section{Results and Discussion}

The in situ and ex situ catalytic pyrolysis models for 2000 MTPD of biomass input estimated average pyrolysis oil yields of 438 and $439 \mathrm{~kg} / \mathrm{BDMT}$ respectively. The yields are similar because ex situ yields were adjusted to match in situ pyrolysis yields after personal communication with researchers at NREL. Pyrolysis biofuel yields of 152.6 and 143.5 liters per dry MT of feedstock were obtained. Table 2 describes the key process material yields for the in situ and ex situ catalytic pyrolysis processes.

Insert Table 2 here. 
The in situ bio-oil yield probability distribution is shown in complementary materials Figure 3 (a), while the simulated yield of gasoline from the in situ process model is presented in complementary materials Figure 3 (b). These results indicate that there is a strong relationship between the bio-oil and gasoline yields, but intermediate upgrading steps affect the shape of the final distribution. At low bio-oil yields, the majority of recovered hydrocarbons are in the diesel and fuel oil range and the gasoline yield decreases.

Figure 3 shows the mass flow rates for in situ and ex situ cases. The mass flow rates for the ex situ case are shown in parentheses while the mass flow rates for the in situ case are shown without parentheses. Overall, the rate of mass conversion to fuels for the in situ and ex situ are $12.6 \mathrm{wt} . \%$ and $13.5 \mathrm{wt} . \%$ respectively, which indicates that the ex situ process could have a higher production rate than in situ pyrolysis.

Insert Figure 3 here.

The MFSP probability density function and cumulative distribution function for the in situ and ex situ cases are shown in Figure 4 . The dark shaded regions indicate $10 \%$ to $90 \%$ confidence intervals, and the dashed vertical line shows the base case values, which indicates the baseline value for the MFSP determined from previous efforts at ISU. The base case MFSP for the in situ scenario is $\$ 0.97 /$ liter, whereas, from the uncertainty analysis of this study, a mean value of 
$\$ 1.11 /$ liter is calculated with a standard deviation of 0.29 . In the ex situ case, a mean value of $\$ 1.13 /$ liter was calculated from the uncertainty analysis. The base case value of $\$ 1.40$ falls outside the $90 \%$ confidence interval of the uncertainty MFSP distribution as figure 4 (b) indicates. The high MFSP base case value found in ex situ scenario is based on literature data for bio-oil yield; recent developments at the national laboratories indicates higher ex situ pyrolysis yields leading to lower MFSP estimates (NREL, 2015). Furthermore, differences in the mean and baseline MFSP values are due to the use of probability parameter distributions instead of standard techno-economic assumptions.

Insert Figure 4 here.

The uncertainty tornado chart in Figure 5 (a) shows the in situ catalytic pyrolysis parameter uncertainty impact on MFSP. Bold legends indicate parameters with high significance at the $0.05 p$-value level. The tornado chart features box plots with gates that indicate the minimum and maximum ranges of the MFSP based on changes to each parameter value. The $\mathrm{min} / \mathrm{max}$ ranges are analogous to the values derived from a sensitivity analysis. The colored box areas are the 0.25 and 0.75 quartile region of MFSP values for the given parameter. The vertical white lines indicate the mean MFSP value. Figure 5 (a) highlights important differences with traditional sensitivity analysis plots (traditional tornado charts). Traditional sensitivity analysis can only indicate the minimum and maximum ranges of MFSP changes by varying each parameter. However, the historical data and experimental data collected in this study suggest 
that the minimum and maximum value for each parameter are less likely to occur than the values within the $0.25 / 0.75$ quartile, which indicates that parameters with a wide range of values may have much narrower influence on MFSP than expected. For example, feedstock cost has a wider range of possible MFSP values than Internal Rate of Return (IRR) and total project investment, but a narrower range within the $0.25 / 0.75$ quartiles than IRR and total project investment. This suggests that feedstock cost may have a lesser influence on the MFSP than other financial assumptions. Furthermore, this new approach is able to determine whether a parameter tends to have a positive or negative influence on the MFSP. For instance, the feedstock distribution is skewed towards lower MFSP values and is therefore more likely to result in a lower MFSP than the average feedstock cost would suggest. This finding contrasts with traditional sensitivity analysis, which does not provide any likelihood information for the range of MFSP values.

The uncertainty tornado chart ranks parameters by their influence on MFSP with the largest direct influence (higher parameter values leading to higher MFSP) shown at the top and largest inverse influence shown at the bottom. For examples, higher electricity prices reduce the MFSP because in situ catalytic pyrolysis exports electricity to the grid; higher hydrotreating catalyst life also reduces the MFSP due to the reduction of hydrotreating catalyst replacement costs per year; higher biochar yield has an inverse impact on MFSP because it correlates with a lower biooil yield, which leads to a lower upgraded fuel production. Feedstock price, internal rate of return, total project investment and bio-oil yield have the greatest impact on the MFSP, therefore they are the crucial parameters that may heavily influence the economic performance of the process. With neither in-situ nor ex-situ fast pyrolysis achieving commercial 
scale, these parameters shed light on potential ways to improve the economic performance of in-situ fast pyrolysis. Among all the parameters, bio-oil yield has a significantly wider range of both possible MFSP values and $0.25 / 0.75$ quartile values than other parameters, which suggests that bio-oil yield has a dominant impact on the MFSP. It is notable that some of the minimum possible MFSP values caused by bio-oil yield changes are below zero. This suggests that in some cases, although statistically unlikely, the biorefinery facility could make sufficient profits from the sale of a co-product such as electricity.

Insert Figure 5 here.

The uncertainty tornado chart for the ex situ pyrolysis scenario is shown in Figure 5 (b). It is found that feedstock price, internal rate of return, total project investment, electricity consumption, biochar yield and electricity price are the most impactful parameters on the MFSP. In this case, IRR and total project investment have wider $0.25 / 0.75$ quartile MFSP value ranges than feedstock price. Therefore, IRR and total project investment may have greater impact on the MFSP. Electricity is generated in the ex situ case, therefore, electricity consumption, which is a negative value, has positive impact on MFSP and electricity price has an inverse impact on MFSP. Higher biochar yield has an inverse impact on MFSP due to the same reason discussed in in situ case.

Figure 6 demonstrates the side-by-side MFSP comparison for the in situ and ex situ scenarios based on previous studies (a) and this study (b). The dots indicate the mean of the MFSP, while 
the lines indicate standard deviation. In the initial analysis, data from previous research in our groups and literature available in 2012 were selected and the same uncertainty analysis methods described in this paper were employed. As figure 6 (a) shows, this initial analysis suggests that in situ catalytic pyrolysis might be more economic than ex situ, with the expected MFSP of $\$ 1.11$ per liter and $\$ 1.40$ per liter respectively. Both cases have large error bars (greater than \$0.29 per liter), which indicate large uncertainty. Figure 6 (b) is a revision of the analysis that was informed by recent experimental data as discussed in the method section. These results indicate that in situ and ex situ catalytic pyrolysis are expected to have a similar MFSP, $\$ 1.11$ per liter and $\$ 1.13$ per liter respectively. This uncertainty analysis suggests that ex situ catalytic pyrolysis is expected to have a smaller standard deviation than in situ catalytic pyrolysis, therefore, there could be greater techno-economic risk associated with the in situ case.

Insert Figure 6 here. 


\section{Conclusion:}

This techno-economic study calculates and compares two different catalytic fast pyrolysis pathways: in situ and ex situ. Best-fit distributions and Monte Carlo methods are employed in to investigate the uncertainty of MFSP estimates.

Uncertainty analysis shows that in situ catalytic pyrolysis is expected to have a similar MFSP with ex situ catalytic pyrolysis, \$1.11 per liter and \$1.13 per liter respectively. However, in situ catalytic pyrolysis has a greater standard deviation compared to the ex situ catalytic pyrolysis scenario based on recent experimental findings. This suggests that ex situ pyrolysis could mitigate some commercialization uncertainty in fast pyrolysis biorefineries.

\section{Acknowledgement:}

This project was made possible by support from the US Department of Energy and Pacific Northwest National Laboratory through Contract Number 167288. The authors would like to acknowledge Rajeeva Thilakaratne for developing the baseline process models. 


\section{References:}

1. Adam, J., Antonakou, E., Lappas, A., Stöcker, M., Nilsen, M.H., Bouzga, A., Hustad, J.E., Øye, G., 2006. In situ catalytic upgrading of biomass derived fast pyrolysis vapours in a fixed bed reactor using mesoporous materials. Microporous Mesoporous Mater. 96, 93-101.

2. Agblevor, F.A., Beis, S., Mante, O., Abdoulmoumine, N., 2010. Fractional Catalytic Pyrolysis of Hybrid Poplar Wood. Ind. Eng. Chem. Res. 49, 3533-3538.

3. Aho, A., Kumar, N., Eränen, K., Salmi, T., Hupa, M., Murzin, D.Y., 2008. Catalytic pyrolysis of woody biomass in a fluidized bed reactor: Influence of the zeolite structure. Fuel 87, 2493-2501.

4. Aho, A., Kumar, N., Lashkul, A.V., Eranen, K., Ziolek, M., Decyk, P., Salmi, T., Holmbom, B., Hupa, M., Murzin, D.Y., 2010. Catalytic upgrading of woody biomass derived pyrolysis vapours over iron modified zeolites in a dual-fluidized bed reactor. Fuel 89, 1992-2000.

5. Anex, R.P., Aden, A., Kazi, F.K., Fortman, J., Swanson, R.M., Wright, M.M., Satrio, J.A., Brown, R.C., Daugaard, D.E., Platon, A., Kothandaraman, G., Hsu, D.D., Dutta, A., 2010. Technoeconomic comparison of biomass-to-transportation fuels via pyrolysis, gasification, and biochemical pathways. Fuel 89, Supplement 1, S29-S35.

6. Bridgwater, A.V., Toft, A.J., Brammer, J.G., 2002. A techno-economic comparison of power production by biomass fast pyrolysis with gasification and combustion. Renew. Sustain. Energy Rev. 6, 181-246.

7. Brown, T.R., Thilakaratne, R., Brown, R.C., Hu, G., 2013. Techno-economic analysis of biomass to transportation fuels and electricity via fast pyrolysis and hydroprocessing. Fuel 106, 463-469.

8. Brown, T.R., Wright, M.M., 2014. Techno-economic impacts of shale gas on cellulosic biofuel pathways. Fuel 117, Part B, 989-995.

9. Cheng, Y.T., Jae, J., Shi, J., Fan, W., Huber, G.W., 2012. Production of Renewable Aromatic Compounds by Catalytic Fast Pyrolysis of Lignocellulosic Biomass with Bifunctional Ga/ZSM-5 Catalysts. Angew. Chem. Int. Edit. 51, 1387-1390.

10. EIA, 2014. Annual Energy Outlook 2014. EIA, Washingtion, DC.

11. Greenland, S., 2001. Sensitivity analysis, Monte Carlo risk analysis, and Bayesian uncertainty assessment. Risk Anal. 21, 579-583.

12. Hoffert, M.I., Caldeira, K., Benford, G., Criswell, D.R., Green, C., Herzog, H., Jain, A.K., Kheshgi, H.S., Lackner, K.S., Lewis, J.S., Lightfoot, H.D., Manheimer, W., Mankins, J.C., Mauel, M.E., Perkins, L.J., Schlesinger, M.E., Volk, T., Wigley, T.M.L., 2002. Advanced Technology Paths to Global Climate Stability: Energy for a Greenhouse Planet. Sci. 298, 981-987.

13. Hsu, D.D., 2012. Life cycle assessment of gasoline and diesel produced via fast pyrolysis and hydroprocessing. Biomass Bioenergy 45, 41-47.

14. Lappas, A.A., Samolada, M.C., latridis, D.K., Voutetakis, S.S., Vasalos, I.A., 2002. Biomass pyrolysis in a circulating fluid bed reactor for the production of fuels and chemicals. Fuel 81 , 2087-2095.

15. Mante, O.D., Agblevor, F.A., Oyama, S.T., McClung, R., 2012. The influence of recycling noncondensable gases in the fractional catalytic pyrolysis of biomass. Bioresour. Technol. 111, 482490.

16. Mihalcik, D.J., Mullen, C.A., Boateng, A.A., 2011. Screening acidic zeolites for catalytic fast pyrolysis of biomass and its components. J. Anal. Appl. Pyrolysis 92, 224-232.

17. Mullen, C.A., Boateng, A.A., Mihalcik, D.J., Goldberg, N.M., 2011. Catalytic Fast Pyrolysis of White Oak Wood in a Bubbling Fluidized Bed. Energy Fuels 25, 5444-5451.

18. Myers, C.W., Shangraw, R.F., Devey, M.R., Hayashi, T., 1986. Understanding Process Plant Schedule Slippage and Startup Costs. RAND Corporation. 
19. NREL, 2015. Process Design and Economics for the Conversion of Lignocellulosic Biomass to Hydrocarbon Fuels. National Renewable Energy Laboratory, Golden, CO., NREL Report No. NREL/TP-5100-62455

20. Olazar, M., Aguado, R., Bilbao, J., Barona, A., 2000. Pyrolysis of sawdust in a conical spouted-bed reactor with a HZSM-5 catalyst. AIChE J. 46, 1025-1033.

21. Ou, L., Brown, T.R., Thilakaratne, R., Hu, G., Brown, R.C., 2014. Techno-economic analysis of colocated corn grain and corn stover ethanol plants. Biofuels Bioprod. Biorefin. 8, 412-422.

22. Ou, L., Thilakaratne, R., Brown, R.C., Wright, M.M., 2015. Techno-economic analysis of transportation fuels from defatted microalgae via hydrothermal liquefaction and hydroprocessing. Biomass Bioenergy. 72, 45-54.

23. Paasikallio, V., Agblevor, F., Oasmaa, A., Lehto, J., Lehtonen, J., 2013. Catalytic Pyrolysis of Forest Thinnings with ZSM-5 Catalysts: Effect of Reaction Temperature on Bio-oil Physical Properties and Chemical Composition. Energy Fuels 27, 7587-7601.

24. Regnier, E., 2007. Oil and energy price volatility. Energy Econ. 29, 405-427.

25. Ruddy, D.A., Schaidle, J.A., Ferrell, J.R., Wang, J., Moens, L., Hensley, J.E., 2014. Recent advances in heterogeneous catalysts for bio-oil upgrading via "ex situ catalytic fast pyrolysis": catalyst development through the study of model compounds. Green Chem. 16, 454-490.

26. Stephens, M.A., 1974. Edf Statistics for Goodness of Fit and Some Comparisons. J. Am. Stat. Assoc. 69, 730-737.

27. PNNL, 2013. Process design and economics for the conversion of lignocellulosic biomass to hydrocarbon fuels. Pacific Northwet National Laboratory, Richland, WA., PNNL-23053.

28. Swanson, R.M., Platon, A., Satrio, J.A., Brown, R.C., 2010. Techno-economic analysis of biomassto-liquids production based on gasification. Fuel 89, Supplement 1, S11-S19.

29. Texas A\&M Forest Service, 2014. Texas Timber Price Trends Reports. Texas A\&M Forest Service.

30. Thilakaratne, R., 2014. Mild catalytic pyrolysis of biomass for production of transportation fuels: a techno-economic analysis. Green Chem. 16, 627.

31. Triantafyllidis, K.S., Iliopoulou, E.F., Antonakou, E.V., Lappas, A.A., Wang, H., Pinnavaia, T.J., 2007. Hydrothermally stable mesoporous aluminosilicates (MSU-S) assembled from zeolite seeds as catalysts for biomass pyrolysis. Microporous Mesoporous Mater. 99, 132-139.

32. Wright, M.M., Daugaard, D.E., Satrio, J.A., Brown, R.C., 2010. Techno-economic analysis of biomass fast pyrolysis to transportation fuels. Fuel 89, Supplement 1, S2-S10.

33. Yildiz, G., Pronk, M., Djokic, M., van Geem, K.M., Ronsse, F., van Duren, R., Prins, W., 2013. Validation of a new set-up for continuous catalytic fast pyrolysis of biomass coupled with vapour phase upgrading. J. Anal. Appl. Pyrolysis 103, 343-351.

34. Zhang, Y., Brown, T.R., Hu, G., Brown, R.C., 2013. Techno-economic analysis of monosaccharide production via fast pyrolysis of lignocellulose. Bioresour. Technol. 127, 358-365. 
Table 1. Probability density functions (PDF), mean, and $\pm 10 \%$ confidence level values of key parameters that apply to both in situ and ex situ cases.

\begin{tabular}{|c|c|c|c|c|c|}
\hline Parameter & Distribution & & Mean & $\begin{array}{c}\text { Confidence } \\
(10 \%)\end{array}$ & $\begin{array}{c}\text { Confidence } \\
(90 \%)\end{array}$ \\
\hline $\begin{array}{l}\text { Industrial Natural Gas Price } \\
\left(\$ / \mathrm{m}^{3}\right)\end{array}$ & $i$ & Lognormal & 0.22 & 0.14 & 0.31 \\
\hline $\begin{array}{l}\text { Industrial Electricity Price } \\
\text { (c/kWh) }\end{array}$ & & Normal & 6.05 & 5.00 & 7.09 \\
\hline Pine pulpwood (\$/MT) & & Lognormal & 78.69 & 67.21 & 90.18 \\
\hline Gasoline Wholesale (\$/liter) & & Lognormal & 0.47 & 0.24 & 0.76 \\
\hline Diesel Wholesale (\$/liter) & & Lognormal & 0.46 & 0.16 & 0.77 \\
\hline Catalyst to Biomass Ratio & I & Triangular & 3.83 & 1.23 & 7.08 \\
\hline Hydrotreating Yield (wt. \%) & & Triangular & 0.44 & 0.43 & 0.45 \\
\hline $\begin{array}{l}\text { First Stage HDO Catalyst } \\
\text { Cost (\$) }\end{array}$ & & Triangular & 60.00 & 43.42 & 76.58 \\
\hline $\begin{array}{l}\text { Second Stage HDO Catalyst } \\
\text { Cost (\$) }\end{array}$ & 1 & Triangular & 18.50 & 13.32 & 24.61 \\
\hline $\begin{array}{l}\text { Second Stage HDO LHSV } \\
(1 / \mathrm{h})\end{array}$ & & Triangular & 0.24 & 0.16 & 0.33 \\
\hline Capital Cost (\$) & 1 & Triangular & 1.10 & 0.97 & 1.26 \\
\hline $\begin{array}{l}\text { Hydrotreating Catalyst Life } \\
\text { (years) }\end{array}$ & & Triangular & 1.17 & 0.77 & 1.61 \\
\hline $\begin{array}{l}\text { Compression Requirement } \\
\text { Factor }\end{array}$ & & Triangular & 1.00 & 0.89 & 1.11 \\
\hline $\begin{array}{l}\text { Hydrogen Consumption } \\
\text { Factor }\end{array}$ & $\therefore$ & Triangular & 1.00 & 0.89 & 1.11 \\
\hline
\end{tabular}


Table 2. Key process material yields for the in situ and ex situ catalytic pyrolysis process.

\begin{tabular}{|l|c|c|}
\hline Scenario & In Situ & Ex Situ \\
\hline Gas Species (kg/BDMT) & 321.2 & 320.3 \\
\hline Pyrolysis Oil (kg/BDMT) & 438.0 & 438.7 \\
\hline Char (kg/BDMT) & 240.8 & 241.0 \\
\hline Natural Gas Utilized (MT/day) & 73.9 & $\mathrm{NA}$ \\
\hline Gasoline \& Diesel Blendstock Yield (wt. \% dry & 12.6 & 13.5 \\
\hline biomass) & & \\
\hline Gasoline \& Diesel Blendstock Yield (liter/dry MT) & 152.6 & 143.5 \\
\hline
\end{tabular}




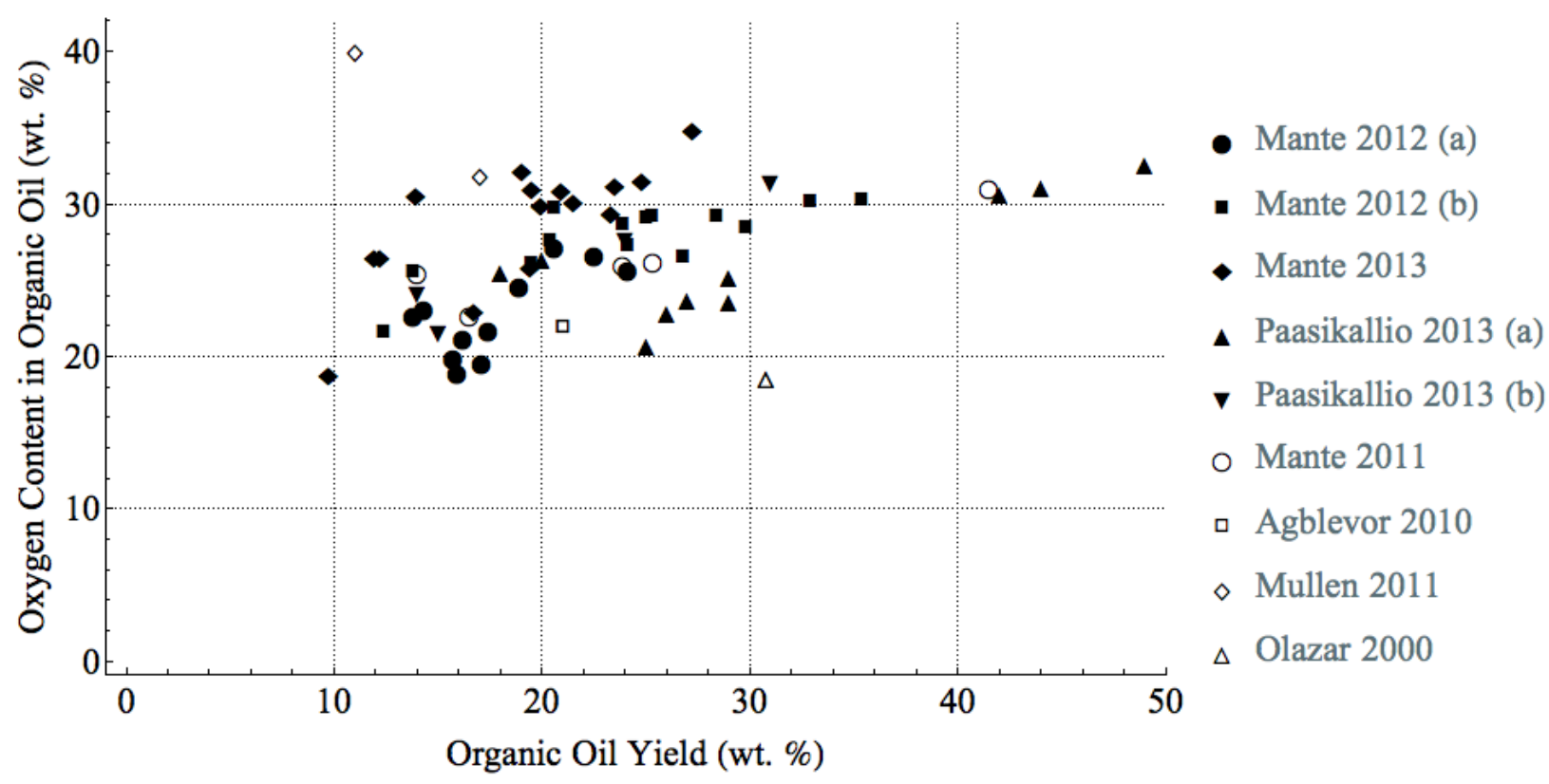

Figure 1. In situ catalytic pyrolysis organic oil yield and oxygen content reported by various sources. 


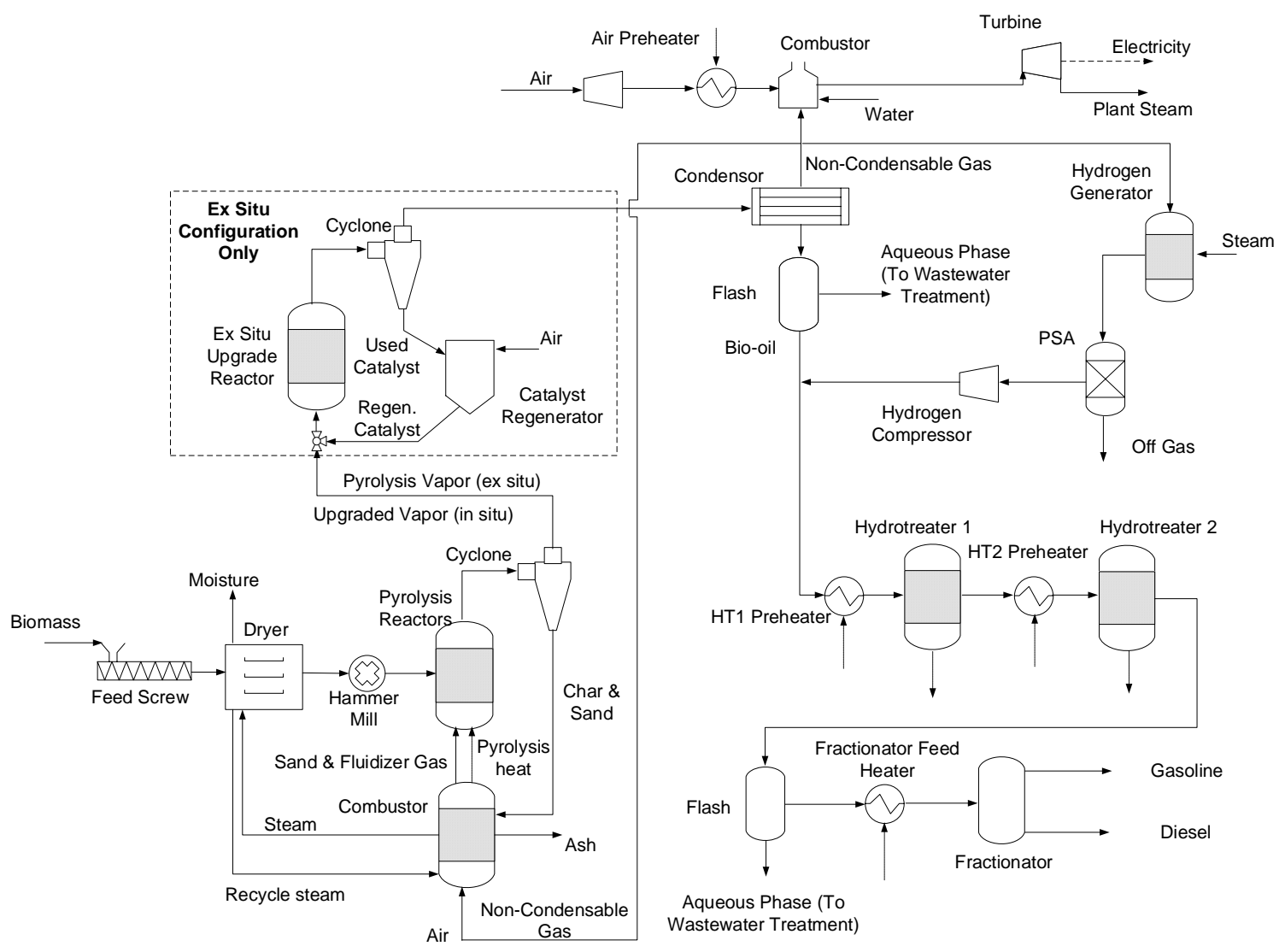

Figure 2. Process diagram for production of transportation biofuel via in situ and ex situ catalytic pyrolysis. 


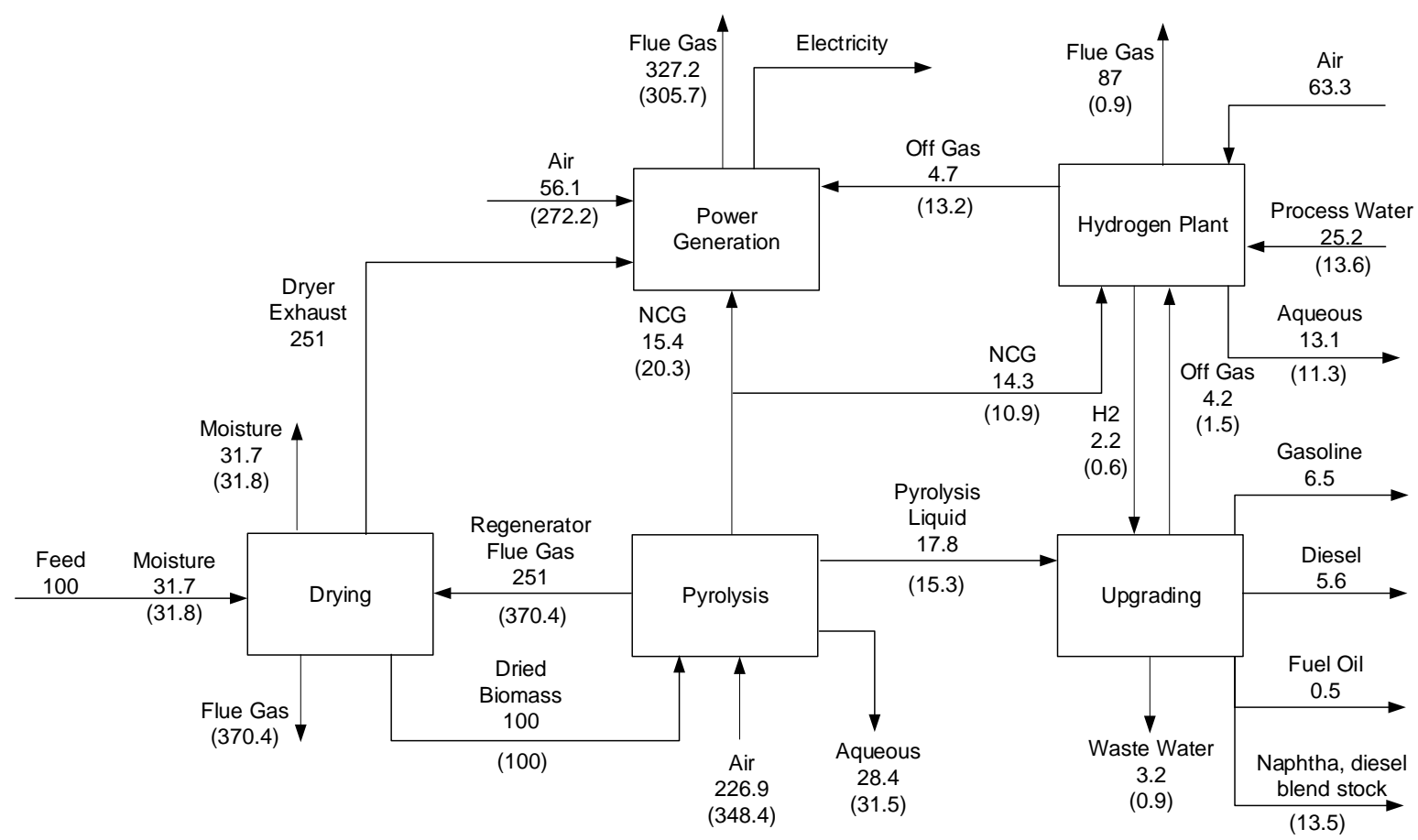

Figure 3. Material flow rates for in situ and ex situ (shown in parenthesis) catalytic pyrolysis process. 
(a)
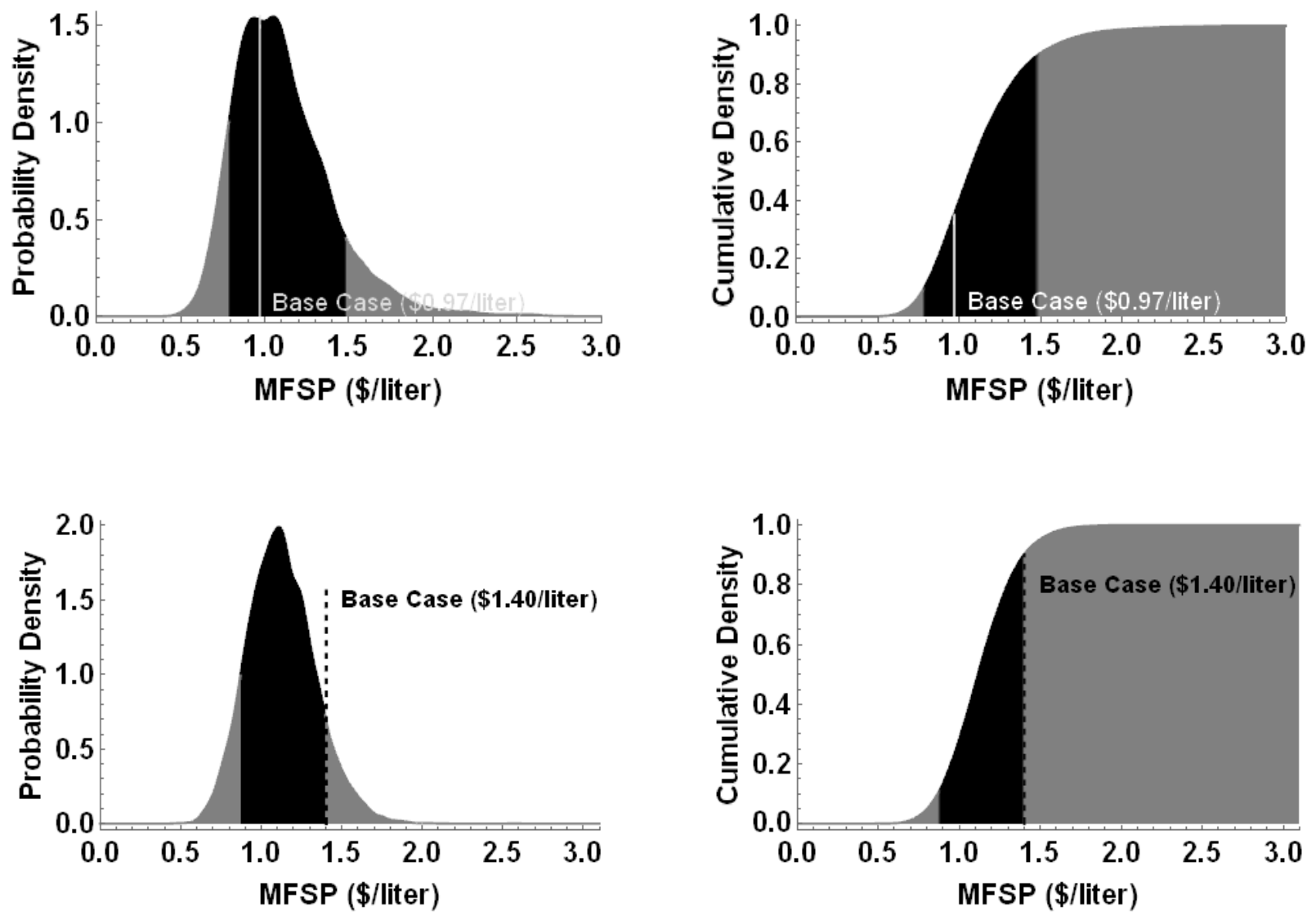

Figure 4. Probability density function and cumulative distribution function of Minimum FuelSelling Price (MFSP) of In situ (a) and ex situ (b) catalytic pyrolysis. Confidence levels of 10 and $90 \%$ are indicated by the dark shaded region. 
(a)

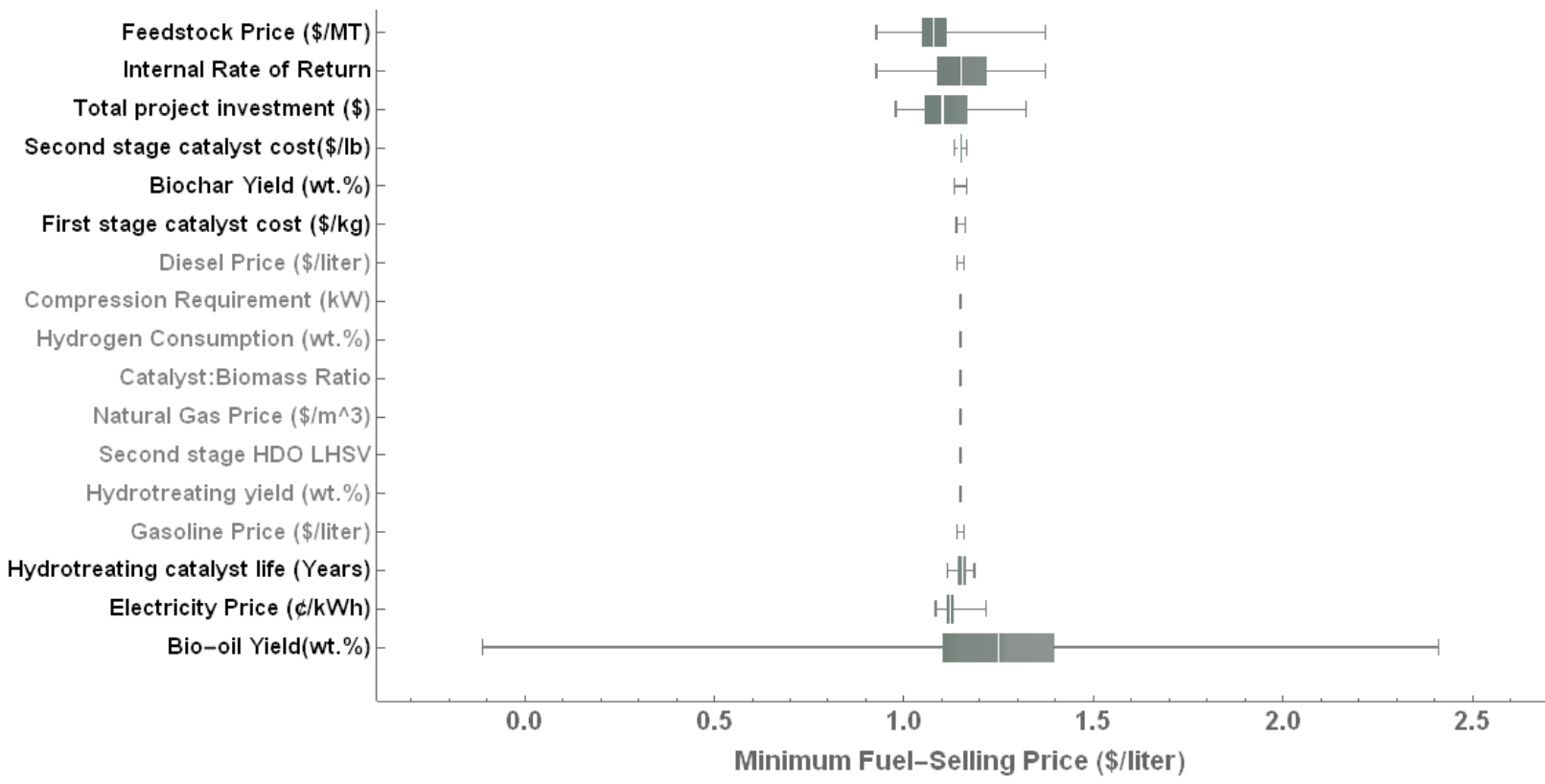

(b)

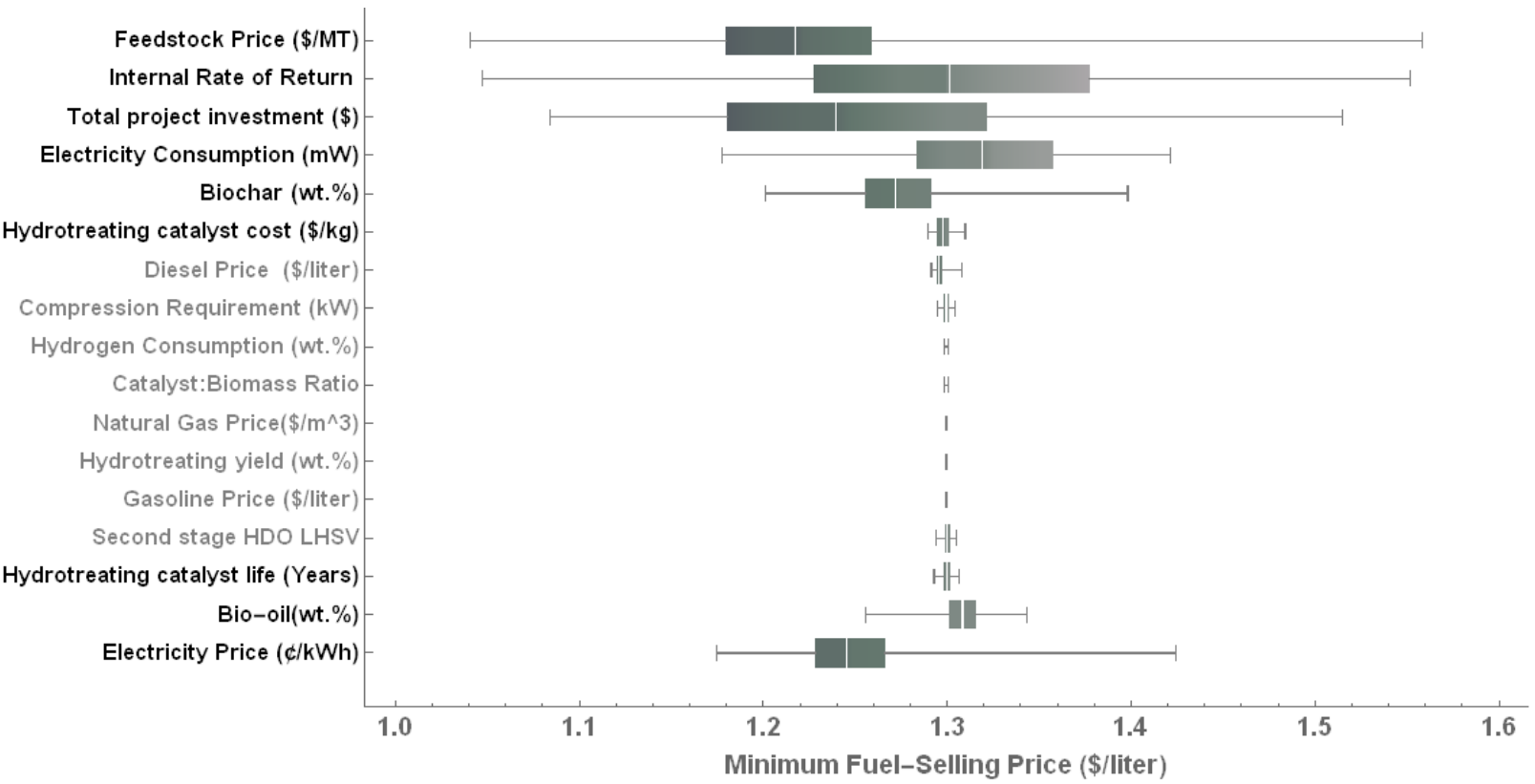

Figure 5. In situ (a) and ex situ (b) catalytic pyrolysis parameter uncertainty impact on the MFSP.

Gates indicate min/max MFSP range; boxes indicate $0.25-0.75$ quantiles of the MFSP; white

vertical lines show the mean MFSP value. Bold legends indicate significant $(p<0.05)$ parameters. 


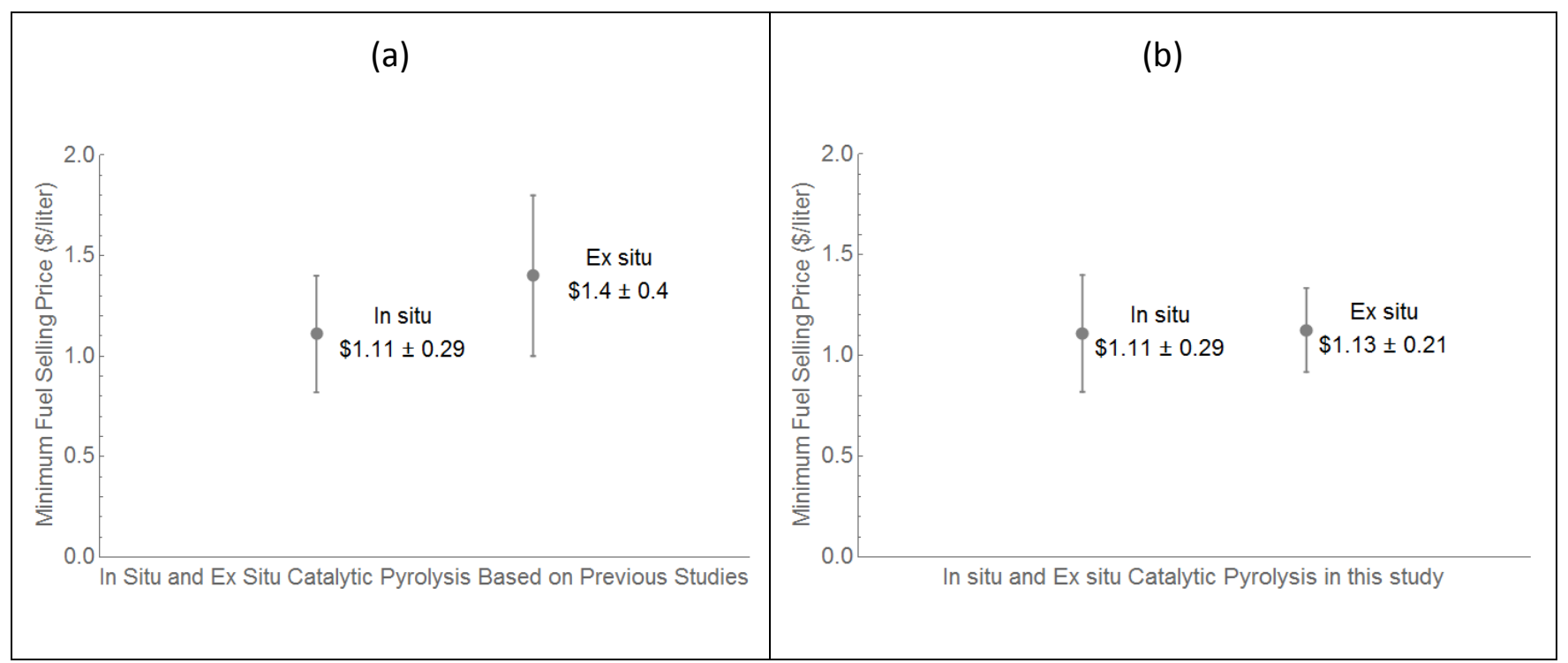

Figure 6. Uncertainty range comparison of in situ MFSP to ex situ catalytic pyrolysis MFSPs

based on previous (a) and recent (b) experimental results. 